\section{Early and late complications associated with open modified janeway gastrostomy, under local anesthesia in patients with head \&}

\author{
neck tumors.
}

\author{
Fatima Zehra Khan, Mir Arsalan Ali, Shafiq Ur Rehman, Syed \\ Mustafa Ali Shah, Maheen Nisar \& Zohaib Jawed Abubaker \\ Dr. Ziauddin Hospital, Karachi-Pakistan
}

Doi: 10.29052/IJEHSR.v8.i3.2020.153-158

Corresponding Author Email:

drfatima.khan24@gmail.com

Received 21/01/2020

Accepted 11/04/2020

First Published 01/09/2020

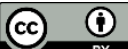

(C) The Author(s). 2020 Open Access This article is distributed under the terms of the Creative Commons Attribution 4.0 International License (http://creativecommons.org/licenses/by/4.0/)

OPEN

ACCESS

\begin{abstract}
Background: Percutaneous Endoscopic Gastrostomy (PEG) is the primary modality for patients requiring long-term enteric feeding and stomach decompression, it has the potential for complications. Therefore, an open surgical gastrostomy presents as an appropriate alternative for patients not viable for an endoscopic approach. The purpose of the study was to assess the complications associated with Open Modified Janeway Gastrostomy $(\mathrm{OMJG})$ in patients with head \& neck tumors and determine their post-operative pain and satisfaction scores.

Methodology: A cross-sectional study was conducted at Ziauddin Hospital, North Nazimabad Campus, Karachi, from May 2015 and November 2019. Patients undergoing Open Modified Janeway Gastrostomy were included in this study. Patients with over 18 years of age and who had feeding needs extending beyond 30 days were included in this study. Outcomes measured included length of stay, operating time, complications, surgical satisfaction and post-operative pain. Chi-square test, with a 95\% confidence interval, was used to evaluate any association of complications with patient demography and post-treatment parameters.

Results: A cross-sectional study was conducted at Ziauddin Hospital, North Nazimabad Campus, Karachi, from May 2015 and November 2019. Patients undergoing Open Modified Janeway Gastrostomy were included in this study. Patients with over 18 years of age and who had feeding needs extending beyond 30 days were included in this study. Outcomes measured included length of stay, operating time, complications, surgical satisfaction and post-operative pain. Chi-square test, with a 95\% confidence interval, was used to evaluate any association of complications with patient demography and post-treatment parameters.

Conclusion: OMJG was found an effective procedure for the insertion of a feeding tube when endoscopic procedures are not feasible, with minimal complications and post-operative pain. It provides more cumulative benefits than other available methods.
\end{abstract}

\title{
Keywords
}

Gastroscopy, Wound Infection, Surgical Stapler, Gastroscopic Surgery, Gastroscopic Surgical Procedures, Catheterization.

\section{Check for updates}




\section{Introduction}

Percutaneous endoscopic gastrostomy (PEG) is considered as the most effective and simple technique among patients requiring long-term enteric feeding and stomach decompression? Indications include head and neck cancers, Crohn's disease, cystic fibrosis, and hypercatabolic states ${ }^{1}$. Although generally, it is a safe procedure but does have the potential for complications, such as sensitivity reactions, gastrointestinal perforation, infection, and bleeding ${ }^{2}$. Limitations include tube dislodgement, obstruction of tubes by residual food, regular replacements, as well as relative expense ${ }^{1,2}$. It is also impossible to access the stomach endoscopically in patients with head and neck tumors, and esophageal strictures ${ }^{1}$. An open surgical gastrostomy is then recommended for patients not viable for an endoscopic approach ${ }^{3}$.

Surgical gastrostomy can be performed by laparotomy or by laparoscopy, where the less invasive laparoscopic access is preferred ${ }^{1}$. In addition to overcoming the limitations faced by PEG, it has the added advantage of allowing suturing of the stomach to the anterior abdominal wall, hence decreasing the risk of tube displacement and intra-peritoneal infections ${ }^{4}$. In laparoscopic gastrostomy, according to Janeway an endoscopic stapling device is used to create a gastric tube from the stomach fold and left uninterrupted for enteral alimentation $^{5}$. The main advantage of this minimally invasive procedure lies in the permanency of the gastrostomy creation of a permanent gastrostomy, as well as undemanding routine aftercare with the detachable catheter easily changed by the patients $^{6-8}$.

This study assesses the early ( $<14$ days postsurgery) and late (>14 days post-surgery) complications associated with Open Modified Janeway Gastrostomy (OMJG), along with postoperative pain and patient satisfaction, in patients with head \& neck tumors.

\section{Methodology}

This cross-sectional study was conducted after obtaining ethical approval from the Ziauddin Ethics Review Committee, and informed consent was acquired from each participant before their inclusion in the study. Patients undergoing Janeway Gastrostomy, at Ziauddin Hospital, North Nazimabad Campus, Karachi between May 2015 and December 2018 were included in this study.

27 patients who underwent this procedure were over 18 years of age and had feeding needs extending beyond 30 days. This included patients with obstructive tumors of the mouth, pharynx, larynx and esophagus, patients with central nervous system tumors and neuromuscular disease, with endoscopically impassable tumors and those with recurrent gastrostomy prolapse. All hemodynamically unstable patients were excluded from this study, as well as children, patients with gastric neoplasms, massive ascites and active gastritis. Patients with unfavorable anatomies, such as in the case of the high intrathoracic position of the stomach and previous gastrostomy, were also excluded. Patients were followed after surgery for six months or until the time of death. Early complications assessed included tube migration/ rupture, peristomal leak, tube blockage, gastric outlet obstruction, wound infection/ pain, and tube dislodge. Late complications assessed included peritonitis, gastrocolic fistula, buried bumper, hyper granulation and infection. The form included information on demographics as well as type, site, and stage of cancer. The outcome of the surgery, including the length of stay, operating time, and Early and Late complications, were also recorded by the principal investigator in a predefined questionnaire.

Open surgical gastrostomy was performed under local anesthesia with 1\% lidocaine. The incision area was painted with pyodine solution, and an upper midline incision, 7 to $10 \mathrm{~cm}$ long was made. After opening the abdominal cavity, the stomach was grasped at the lower section of 
the greater curvature and placed on the abdominal wall. The gastrointestinal anastomosis (GIA) 75-mm automatic stapler was used with initial positioning such that it was directed at the pylorus. It was used to create a longitudinal gastric tube, approximately $6 \mathrm{~cm}$ long, from the anterior wall of the stomach, with its opening located at the upper end. A running 2-0 vicryl suture was used to reinforce the stapler margins. A stab wound was created under the left costal margin to lead the gastric tube out through the abdominal wall, after the application of local anesthesia. The abdomen was then closed with interrupted sutures with a gastrostoma formed at the end of the tube. A 24-F Foley catheter was inserted through the gastrostoma, and left there for the next few weeks, providing easy removal between meals.

Data was analyzed on IBM SPSS version 20.0 (Armonk, NY, USA), and frequencies were calculated using descriptive statistics. Chi-square test was used to find associations between the appropriate categorical variables, with $\mathrm{p}$-values less than 0.05 were taken as significant.

\section{Results}

A total of 27 patients participated in this study, with 17 (63\%) males and 10 (37\%) females. The mean age of the participants was $56 \pm 11.9$ years. According to the TNM (Tumor, Node, Metastasis) classification, 16 (59.3\%) had stage IV, 10 (37\%) stage III and 1 (3.7\%) stage II cancer. The survival rate after a six-month follow-up was $77.8 \%$. The cause of death was not associated with OMJG. Post-surgery, three patients presented with complications, i.e., superficial wound infection. 2 (7.4\%) patients presented with early complications and 1(3.7\%) had late complications. No serious complications were reported. There was no association of mortality with cancer stage $(p=0.386)$, early complications (0.326), late complications (0.586), gender (0.831) or age (0.336). No significant associations were seen between complications and gender, mortality or cancer stage, as noted in table 1 . The highest pain scores recorded were on average, $3.78 \pm 1.22$ (on a scale of $0-10$ with 10 being the most pain).

Table 1: Complications and relationship with other respective variables after Open Modified Janeway Gastrostomy

\begin{tabular}{|c|c|c|c|c|c|c|}
\hline \multirow[t]{2}{*}{ Variables } & & \multicolumn{2}{|c|}{ Major Complications } & \multicolumn{2}{|c|}{ Minor Complications } & \multirow[t]{2}{*}{ p-value } \\
\hline & & Present & Normal & Present & Normal & \\
\hline \multirow[t]{3}{*}{ Gender } & Male & $2(7.4)$ & $15(55.6)$ & $1(3.7)$ & $16(59.3)$ & \multirow[t]{3}{*}{0.58} \\
\hline & Female & $1(3.7)$ & $9(33.3)$ & $0(0.0)$ & $10(37.0)$ & \\
\hline & Total & $3(11.1)$ & $24(88.9)$ & $1(3.7)$ & $26(96.3)$ & \\
\hline \multirow[t]{3}{*}{ Outcome } & Alive & $2(7.4)$ & 19(70.4) & $1(3.7)$ & $20(74.1)$ & \multirow[t]{3}{*}{0.885} \\
\hline & Death & $1(3.7)$ & $5(18.5)$ & $0(0.0)$ & $6(22.2)$ & \\
\hline & Total & $3(11.1)$ & $24(88.9)$ & $1(3.7)$ & $26(96.3)$ & \\
\hline \multirow[t]{5}{*}{ Cancer Stage } & Stage 1 & $0(0.0)$ & $0(0.0)$ & $0(0.0)$ & $0(0.0)$ & \multirow[t]{5}{*}{0.797} \\
\hline & Stage 2 & $0(0.0)$ & $1(3.7)$ & $0(0.0)$ & $1(3.7)$ & \\
\hline & Stage 3 & $2(7.4)$ & $8(29.6)$ & $0(0.0)$ & $10(37.0)$ & \\
\hline & Stage 4 & $1(3.7)$ & $15(55.6)$ & $1(3.7)$ & $15(55.6)$ & \\
\hline & Total & $3(11.1)$ & $24(88.9)$ & $1(3.7)$ & $26(96.3)$ & \\
\hline \multirow[t]{3}{*}{ Hospital Stay } & 1 day & $3(11.1)$ & $22(81.5)$ & $1(3.7)$ & $24(88.9)$ & \multirow[t]{3}{*}{0.540} \\
\hline & 2 days & $0(0.0)$ & $2(7.4)$ & $0(0.0)$ & $2(7.4)$ & \\
\hline & Total & $3(11.1)$ & $24(88.9)$ & $1(3.7)$ & $26(96.3)$ & \\
\hline
\end{tabular}

${ }^{*} \mathrm{p}$-value $<0.05$ were considered significant 
Participants reported insignificant changes in activities, sleep and mood post-surgery, as noted in Table 2. Notably, patient satisfaction scores after OMJG were found to be noticeably high, with a mean of $8.44 \pm 0.89$ (on a scale of 0-10 with 10 being the most satisfied), indicating general satisfaction after opting for this procedure.

Table 2: Patient feedback after Open Modified Janeway Gastrostomy

\begin{tabular}{|c|c|c|c|}
\hline Post Treatment Parameters & & Mean \pm SD & p-value \\
\hline \multirow[t]{2}{*}{ Pain in the first $24 \mathrm{hrs}$} & Most & $3.78 \pm 1.22$ & 0.391 \\
\hline & Least & $2.52 \pm 0.85$ & 0.619 \\
\hline \multirow[t]{2}{*}{ Activities affected } & On bed & $1.48 \pm 0.64$ & 0.668 \\
\hline & Out of bed & $1.19 \pm 0.48$ & 0.665 \\
\hline \multirow[t]{2}{*}{ Sleep } & Difficulty falling asleep & $1.15 \pm 0.36$ & 0.366 \\
\hline & Difficulty staying asleep & $1.15 \pm 0.36$ & 0.366 \\
\hline \multirow[t]{4}{*}{ Mood } & Anxious & $1.37 \pm 0.69$ & 0.430 \\
\hline & Depressed & $0.85 \pm 0.86$ & 0.716 \\
\hline & Frightened & $0.44 \pm 0.51$ & 0.183 \\
\hline & Helpless & $0.63 \pm 0.69$ & 0.732 \\
\hline \multirow[t]{3}{*}{ Side effects } & Drowsy & $1.63 \pm 1.39$ & 0.586 \\
\hline & Nausea & $0.07 \pm 0.27$ & 0.540 \\
\hline & Dizzy & $0.07 \pm 0.27$ & 0.540 \\
\hline Other & Satisfaction & $8.44 \pm 0.89$ & 0.358 \\
\hline
\end{tabular}

*No P-values were found to be significant

*Each parameter was recorded on a scale of 1-10; 1-lowest affect \& 10-most affect.

\section{Discussion}

Gastrostomy tube insertion is a widely performed procedure allowing for the short- or long-term nutrition of patients unable to otherwise maintain their required caloric intake, with indications ranging from simple swallowing disabilities, as in luminal obstruction from tumors or strictures, to hypercatabolic states, such as patients with extensive burn injuries, or Crohn's disease ${ }^{9}$, and most frequently in patients with neurological diseases due to stroke or malignancies of the head and neck ${ }^{10}$.

They were developed as a way to overcome feeding difficulties in obstruction of the esophagus ${ }^{11,12}$. The technique remained primarily surgical, mostly employing the purse-string suture as described by Stamn in $1894^{13}$, for a large part of the next century, until the development of PEG by Gauderer and Ponsky ${ }^{14}$, in 1980. The technique was well received for being inherently non-invasive, and its relative lack of morbidity and mortality.
Broadly speaking, the modern method of insertion of the tube can be divided into three techniques: surgical, insertion via PEG, and radiologically inserted gastrostomy (RIG). RIG was first described not long after PEG, and it boasts many of the same advantages ${ }^{15}$, and as such, both are the preferred modality for routine use of gastrostomy placement, with the surgical methods instead finding their place in providing drainage, rather than the insertion of a feeding tube ${ }^{16}$. However, there are cases where it is not feasible to pass a tube by either method, such as in cases of complete upper gastrointestinal tract obstruction, certain anatomical abnormalities, the interposition of colon or liver between the abdominal wall and the stomach, or impossibility to set the stomach adjacent to the abdominal wall and perform transillumination, which may be additionally complicated by ascites, obesity, previous gastric resection, secondary abdominal adhesions due to previous surgeries and hepatomegaly ${ }^{1,17}$. 
Currently, available surgical approaches are varied based on the type of incision made. The Janeway technique involves the construction of a mucosalined tube with valve-like control at the gastric end to prevent leakage of irritating gastric content. This method has been found to lead to fewer complications when compared against the Stamn method ${ }^{17}$ and to be more favourable for the patient as compared to the Witzel fistula ${ }^{18}$.

In our study group, of the 27 patients, only 3 (11.1\%) suffered any complications from the procedure. No post-operative mortality due to Open Modified Janeway Gastrostomy was noted. However, while the problems noted in our study were only superficial wound infection, there are accounts more adverse effects such as stomal stenosis, stomal degranulation, and aspiration pneumonia, as well as leakage of gastric contents in the literature such as dehiscence and leakage ${ }^{1,19}$.

While laparoscopic surgery traditionally holds the advantage over open surgery, the additional training required clearly returns some of the favour to this approach ${ }^{20,21}$. Worth noting as this point is that after the procedure, patient sleep was found to be practically unaffected, and there were no complaints of any disorienting sensations, like drowsiness or dizziness, perhaps due to the choice of local over general anesthesia.

Patient satisfaction, along with the permanence of the tube and the ease of use for both patients and care takers contribute to the Janeway approach being of the most value in palliative care for patients with feeding difficulties ${ }^{21}$. As such, the impact of the technique on the patient's is of high value as a metric for the virtues of the technique. Our patients were assessed on their outlook on their surgery using the American Pain Society Pain Outcome Questionnaire (APS-POQ) ${ }^{22}$, and the results are summarized in Table 2 . While there was some mention of pain in the first 24 hours of the surgery, the subjects found that it was still well within tolerable limits. There was also only mild disruption in the patient's temperament, and in fact, most patients stated they were very satisfied with their surgery.
Other interesting observations that may be noted are that major complications were more prevalent among groups with more advanced stages of cancer, which is synonymous with published evidence since the individuals may be more vulnerable $^{19}$. Additionally, it was observed that minor complications too more common among patients with advanced stages of cancer, though literature does not offer consistent findings in this regard $^{11,19}$.

The limitations of the study include the low sample size, which prevented us from drawing statistically significant conclusions about the frequency of negative outcomes, pertaining either to death or to complications arising directly due to the procedure. In addition, due to the lack of a comparison group, we were unable to empirically identify potential confounders to the results. Furthermore, the nature of the study required the participants to have a terminal disease (more than half were suffering from a stage 4 malignancy), so any conclusions drawn from their death would be inherently prone to being biased.

\section{Conclusion}

Data of this study supports that the OMJG is an effective procedure for the insertion of a feeding tube when endoscopic procedures are not feasible. While surgical gastrostomy in itself occupies a niche in clinical practice, the OMJG provides more benefits than the other available methods, being both simple and quick to perform, and leading to fewer complications. Due to several limitations in the study, multicentre large scale trials should be conducted in future.

\section{Conflicts of Interest}

None.

\section{Acknowledgement}

The authors would like to acknowledge the support of study participants.

\section{Funding}

None. 


\section{References}

1. Shah R, Shah M. Gastrostomy Tube Replacement. In: StatPearls [Internet]. Treasure Island (FL): StatPearls Publishing; 2019. Available at: https://www.ncbi.nlm.nih.gov/books/NBK482422/

2. Anselmo CB, Tercioti Junior V, Lopes LR, Coelho Neto Jde S, Andreollo NA. Surgical gastrostomy: current indications and complications in a university hospital. Rev Col Bras Cir. 2013; 40(6):458-462.

3. Delegge $\mathrm{MH}$. Gastrostomy tubes: Complications and their management. 2014; 2552(14). Available at: https://peakgastro.com/wpcontent/uploads/2013/10/Feeding-Tubes-PEGTubes.pdf

4. Bravo JG, Ide E, Kondo A, Moura DT, Moura ET, Sakai $P$, Bernardo WM, Moura EG. Percutaneous endoscopic versus surgical gastrostomy in patients with benign and malignant diseases: a systematic review and meta-analysis. Clinics. 2016;71(3):169178.

5. Ambur $\mathrm{V}$, Taghavi S, Jayarajan $\mathrm{S}$, Gaughan J, Toyoda Y, Dauer E, Sjoholm LO, Pathak A, Santora T, Goldberg AJ. Comparing open gastrostomy tube to percutaneous endoscopic gastrostomy tube in heart transplant patients. Ann Med Surg (Lond). 2016;7:71-74.

6. Ritz JP, Germer CT, Buhr HJ. Laparoscopic gastrostomy according to Janeway. Surg Endosc. 1998; 12(6):894-897.

7. Arnal E, Voiglio EJ, Robert M, Schreiber V, Ceruze P, Caillot JL. Gastrostomie tubulisée coelioscopique : une solution avantageuse pour une nutrition entérale autonome [Laparoscopic Janeway gastrostomy: an advantageous solution for selfsufficient enteral feeding]. Ann Chir. 2005;130(10):613-617.

8. Kwon RS, Banerjee $S$, Desilets D, Diehl DL, Farraye FA, Kaul V, Mamula P, Pedrosa MC, Rodriguez SA, Varadarajulu S, Song LM. Enteral nutrition access devices. Gastrointest Endosc. 2010; 72(2):236-248.

9. Burkitt P, Carter LM, Smith AB, Kanatas A. Outcomes of percutaneous endoscopic gastrostomy and radiologically inserted gastrostomy in patients with head and neck cancer: a systematic review. Br J Oral Maxillofac Surg. 2011; 49(7):516-520.

10. Brewer LA 3rd. History of surgery of the esophagus. Am J Surg. 1980; 139(6):730-743.

11. Celestin LR. Permanent intubation in inoperable cancer of the oesophagus and cardia: a new tube. Ann R Coll Surg Engl.1959; 25(2):165-170.

12. Stamn M. Gastrostomy: a new method. Med News 1894;65:324
13. Gauderer MW, Ponsky JL, Izant RJ Jr. Gastrostomy without laparotomy: a percutaneous endoscopic technique. J Pediatr Surg. 1980; 15(6):872-875.

14. Preshaw RM. A percutaneous method for inserting a feeding gastrostomy tube. Surg Gynecol Obstet. 1981; 152(5):658-660.

15. Möller P, Lindberg CG, Zilling T. Gastrostomy by various techniques: evaluation of indications, outcome, and complications. Scand J Gastroenterol. 1999; 34(10):1050-1054.

16. Aguayo PS, Herguido NG, Campos JP, Moreno AB, Romero MD, Cunill JL, del Agua IA, Macias MS, Luna PP, Conde SM. New laparoscopic assisted percutaneous gastrostomy. Description and comparison with others gastrostomy types. Clin Nutr ESPEN. 2016; 16:24-29.

17. Ritz JP, Germer CT, Albrecht D, Buhr HJ. Wiederentdeckte Verfahren--Die laparoskopische Gastrostomie nach Janeway im Vergleich zur Witzel-Fistel [Rediscovered techniques--Janeway laparoscopic gastrostomy in comparison with Witzel fistula]. Langenbecks Arch Chir Suppl Kongressbd. 1998;115:1523-1525.

18. McGovern B. Janeway gastrostomy in children with cerebral palsy. J Pediatr Surg. 1984; 19(6):800-802.

19. Vassilopoulos PP, Filopoulos E, Kelessis N, Gontikakis M, Plataniotis G. Competent gastrostomy for patients with head and neck cancer. Support Care Cancer. 1998; 6(5):479-481.

20. Kirby DF. Surgical gastrostomies versus endoscopic gastrostomies: a tube by any other name. Mayo Clin Proc. 1995; 70(9):914-916.

21. Raakow R, Hintze R, Schmidt S, Adler A, Neuhaus P. The laparoscopic Janeway gastrostomy. An alternative technique when percutaneous endoscopic gastrostomy is impractical. Endoscopy. 2001; 33(7):610-613.

22. Gordon DB, Polomano RC, Pellino TA. Revised American Pain Society Patient Outcome Questionnaire (APS-POQ-R) for quality improvement of pain management in hospitalized adults: preliminary psychometric evaluation. J Pain. 2010; 11(11):1172-1186. 